\title{
Effect of Fluoride Gel and Foam on Salivary Fluoride
}

\section{Concentration}

Seyed Akhavan $\mathbf{P}^{1}$, Sayahpour $\mathbf{S}^{2^{*}}$, Momeni $\mathbf{H}^{3}$,Kharazifard $\mathbf{M J}^{4}$

1. Assistant Professor Pediatric Dentistry Dept,Dental Branch of Tehran, Islamic Azad University, Tehran, Iran

2. Post Graduate Student, Pediatric Dentistry Dept,Dental Branch of Tehran, Islamic Azad University, Tehran, Iran

3.Dentist

4.Research member, Dental Research Center, Dentistry Research Institute, Tehran University of Medical Sciences, Tehran, Iran

\begin{tabular}{l}
\hline ARTICLE INFO \\
\hline Article Type \\
Original Article \\
Article History \\
Received: Jan 2017 \\
Accepted:Feb 2017 \\
ePublished: Apr 2017 \\
\hline
\end{tabular}

Keywords:

Saliva,

Fluoride concentration,

Fluoride gel,

Fluoride foam,

\begin{abstract}
Background and Aim: Many studies have shown that various fluoride-containing products can change salivary fluoride concentration. Nowadays, different kinds of topical fluoride gels and foams are used to prevent dental caries. The aim of this study was to evaluate salivary fluoride concentration following the application of 3 different fluoride containing materials at different follow-up intervals.

Materials and Methods: In this cross over clinical trial, 12 dentistry students with the mean age of $25.66 \pm 2.4$ years participated. They had no dental caries or fluoridecontaining restorations, and they had not received any kind of fluoride treatment ,recently. Each participant was entered in 3 intervention sessions in which Topex ${ }^{\circledR} A P F$ gel, Topex APF foam and Cina APF gel were applied followed by a one-week washout period. Before starting the treatment, unstimulated saliva samples were collected. Saliva samples were also collected at 1, 15, 30, and 60 minutes after the treatment, and fluoride concentrations were evaluated by using the ion specific electrode method. Data were analyzed by the use of Kruskal-Wallis and Dunn multiple comparison tests. Results: Salivary concentration was in the maximum range at minute one, after using each type of fluoridated products evaluated in this survey, and it decreased gradually to minute 60 . There was a significant statistical difference in fluoride concentration at minutes 1 and 60 after using Topex ${ }^{\circledR} A P F$ gel in comparison with Topex $® A P F$ foam and Cina APF gel. Furthermore, significant statistical differences in salivary fluoride concentration were reported following the application of Topex $\AA$ APF gel, Cina APF gel and Topex $®$ APF foam $(p<0.001)$. There were no significant differences between Cina APF gel and Topex $® A P F$ foam.

Conclusion: The results of the present study revealed that Topex ${ } A P F$ foam at minute one and Cina APF gel at minute 60 induced higher salivary fluoride concentrations in comparison with the other studied fluoride-containing products.
\end{abstract}

\footnotetext{
Please cite this paper as: Seyed Akhavan P, Sayahpour S,Momeni H,Kharazifard MJ. Effect of Fluoride Gel and Foam on Salivary Fluoride Concentration. J Res Dent Maxillofac Sci. 2017;2(2):16-22
} 


\section{Introduction:}

Tooth decay is still one of the most common chronic dental diseases in all populations with various degrees of severity. ${ }^{(1)}$ It is well-established that topical application of fluoride via different procedures and with the use of different compounds, plays an important role in caries prevention and remineralization. ${ }^{(2)}$ Methods of topical fluoride application include professional topical application and home use of fluoride dentifrice and mouth rinse. ${ }^{(3)}$ Professionally applied topical fluoride agents are available in the forms of liquid, gel, and foam. Since foams and gels are generally applied by using a tray, they provide the advantage of simultaneously applying the fluoride to the entire dentition. ${ }^{(4)}$ Various compositions of fluoride are available, but the most popular compound is Acidulated Phosphate Fluoride (APF). This specialized agent was developed in 1960 s with the use of sodium fluoride $(\mathrm{NaF})$, and contains $1.23 \%$ (12300 parts per million (ppm)) fluoride ions with the $\mathrm{pH}$ of about 3.5.$^{(5)}$ Topical fluoride compounds that contain APF have been the favored vehicle for professional use in caries prevention programs. ${ }^{(6,7)}$ Topical fluoride application may lead to substantial accumulation of fluoride, both on and inside enamel and dentin samples which have been directly treated with these systems. ${ }^{(8,9)}$

Although most clinical references have suggested 4 minutes as the optimal time for fluoride application, ${ }^{(10)}$ some studies have suggested that 4 minutes of fluoride application does not reduce enamel demineralization after the first minute. In addition, reducing the time could decrease the risk of inadvertent ingestion and relevant toxicity in children. ${ }^{(11,12)}$

Fluoride-containing foams are commonly used in dental practice; however, the clinical evidence of their efficacy is not as strong as that of fluoride gel. ${ }^{(13)}$ There are clinical and laboratory data demonstrating that foam is equivalent to gel in terms of fluoride release, ${ }^{(13-15)}$ but foam allows the use of smaller amounts of product to fill the tray, leading to a lower fluoride dose and thereby reducing the risk associated with inadvertent ingestion. ${ }^{(13)}$
Fluoride bioavailability in saliva is used to estimate the anticariogenic potential of fluoridated topical systems, since fluoride diffuses from saliva into the biofilm and its fluid, and acts in remineralization processes at the tooth-biofilm interface. ${ }^{(16)}$ However, the intraoral fluoride retention or substantivity is mainly influenced by userrelated factors, such as age, salivary flow and clearance, behavioral aspects, such as frequency and duration of brushing, amount of toothpaste and other fluoridated products, and post-brushing rinsing pattern. ${ }^{(16,17)}$

Although fluoride absorption into enamel and salivary fluoride retention are the main factors that determine the anticariogenic potential of fluoridated products, little is known about the salivary bioavailability of fluoride after the use of topical agents containing high concentrations of fluoride. Therefore, the aim of the present study was to analyze the amount of fluoride released in saliva after using three different APF systems.

\section{Materials and Methods:}

This single-blind crossover trial study was conducted at the department of pediatric dentistry of Islamic Azad University, Dental Branch of Tehran. Ethical approval of the study was granted by the Ethics Committee of the university. Twelve dentistry students with the mean age of $25.66 \pm 2.4$ years voluntarily participated in the study, and informed consent was received from all the subjects.

All the participants were healthy with no systemic diseases in their medical history. They had good oral health without any pathosis, normal salivary flow rate, and complete natural dentition. They had no orthodontic or prosthodontic appliances and were not using any medications. Moreover, they had no pathologic lesions, faulty dental restorations, active dental caries or fluoride-releasing restorations, and they were also instructed to avoid extra fluoride uptake. ${ }^{(18)}$

Volunteers were randomly assigned to three groups, and the experiment started by using one of the APF agents.At the end of the experiment all the volunteers had used three different products during the three treatment sessions To 
enhance constancy of conditions among all the subjects, a one-week washout period was considered in which the same oral hygiene technique was followed by all the subjects. Therefore, all the participants brushed their teeth with the same type of toothbrush and dentifrice and the same protocol was followed in terms of the recommended frequency and duration of brushing and amount of dentifrice (equal to the head length of the toothbrush).

In the three sessions, Topex ${ }^{\circledR}, 1.23 \%$ APF gel (Sultan Healthcare, Inc., Englewood, NJ, USA), Topex ${ }^{\circledR}, 1.23 \%$ APF foam (Sultan Healthcare, Inc, Englewood, NJ, USA) and Cina $1.23 \%$ APF gel (Cina Bartar Co. Tehran, Iran) were applied. To determine the baseline value of fluoride in each session, unstimulated saliva samples were collected from all the subjects for 5 minutes through expelling saliva into a plastic funnel which was placed in a 9cc polyethylene tube. Saliva samples were stored in a freezer at $-20^{\circ} \mathrm{C}$ until the time of analysis. Then, $1.5-2 \mathrm{~g}$ of gel or $0.3-0.4 \mathrm{~g}$ of foam were applied to the volunteers' teeth using disposable trays for each jaw. The precise weight of the APF agent was measured by a digital scale (Kia Electronic Aras, Tabriz, Iran) with the sensitivity of 0.1-200 g. Both upper and lower trays were simultaneously inserted into each volunteer's mouth and were kept in the mouth for 4 minutes. After the trays were removed, each subject was asked to expel the remaining agent and not to swallow it. Saliva samples were collected from each subject into separate plastic tubes at 1, 15, 30 and 60 minutes after the treatment. All the participants repeated the above process with the three different formulations (crossover). The washout period between each cycle was one week.

In order to measure fluoride ion concentration in saliva, first the frozen samples were kept at $22^{\circ} \mathrm{C}$ to melt. Saliva samples were clarified by centrifugation for 15 minutes at $3000 \mathrm{rpm}$. Therefore, debris and other impurities were precipitated. Afterwards, $2 \mathrm{ml}$ of super clear supernatant liquid was diluted with $2 \mathrm{ml}$ of TISAB III (Total Ionic Strength Adjustment Buffer, Thermo Electron Corp., Beverly, MA, USA) at a 1:1 ratio. ${ }^{(19)}$ The fluoride concentration of saliva was analyzed as ppm using the ion-specific electrode (Orion combination electrode, Thermo Electron Corp., Beverly, MA, USA) and ION meter (629 $\mathrm{PH} / \mathrm{ION}$ meter, Metrohm, Herisau, Switzerland).

The data are expressed as Mean \pm SD. Fluoride concentrations in saliva were analyzed following the application of the three fluoride agents. For comparison of salivary fluoride concentration following the application of the three agents at each time interval, Kruskal-Wallis and Dunn multiple comparison tests were used. In order to compare salivary fluoride release in each group between the time intervals, Friedman and Bonferroni adjusted post hoc tests were used.

\section{Results:}

This study was performed on 12 dentistry students ( 6 males and 6 females) with the mean age of $25.66 \pm 2.4$ years. The mean DMFT index in the current study was $5.66 \pm 1.3$. All the 12 volunteers completed the study and no saliva samples were lost. Unstimulated salivary fluoride levels before (baseline) and at 1, 15, 30 and 60 minutes after the application of the three APF agents are demonstrated in Figure 1 and Table 1.

At the first minute, the highest fluoride concentration was recorded after the use of Topex ${ }^{\circledR}$ APF foam, , while the lowest concentration was reported after the application of Topex ${ }^{\circledR}$ APF foam. A statistically significant difference was reported between the three agents at the first minute $(\mathrm{p}<0.001)$.

In all three systems, a drastic decrease in fluoride content was detected at the 15th minute, but the level was still higher than the baseline.

Moreover, after 60 minutes, salivary fluoride concentration was close to the baseline level for all agents; however, significant differences were observed between the three experimental groups $(\mathrm{p}<0.001)$.

Comparison of the total salivary fluoride content from baseline until 1 hour after the application of the three APF agents demonstrated significant differences $(p<0.001)$ between the time intervals. (Table 1) Baseline fluoride levels of the samples were not statistically different in the three study groups. $(\mathrm{p}=0.5)$. 
Table 1- Salivary fluoride concentration (ppm) after the application of APF agents

\begin{tabular}{|c|c|c|c|c|c|c|}
\hline $\operatorname{Tim}$ & Baseline & 1 minute & 15 minutes & 30 minutes & 60 minutes & \\
\hline & $\begin{array}{l}\text { Mean土SD } \\
\text { (ppm) }\end{array}$ & $\begin{array}{l}\text { Mean } \pm S D \\
\text { (ppm) }\end{array}$ & $\begin{array}{c}\text { Nean }=S D \\
\text { (ppm) }\end{array}$ & $\begin{array}{l}\text { Mean } \pm \text { SD } \\
\text { (ppm) }\end{array}$ & $\begin{array}{c}\text { Nean }=51 \\
\text { (ppm) }\end{array}$ & \\
\hline Cina AlpF gel & $0.006 \pm 0.02$ & $105.9 \pm 71.5$ & $698+4.18$ & $3.31=1.79$ & $1.27 \pm 0.76$ & pe-0.001 \\
\hline Topesst APF gel & $0.07 \pm 0.26$ & $30.5 \pm 18.3$ & $4.6 \pm 5.97$ & $1.83=2.22$ & $0.4 \pm 0.79$ & $\mathrm{p}=0.001$ \\
\hline $\begin{array}{c}\text { Topexp APF } \\
\text { foam }\end{array}$ & $0=0$ & $123.5 \pm 94.11$ & $8.49 \pm 6.35$ & $3.12 \pm 2.1$ & $1.23 \pm 0.59$ & $\mathrm{p}<-0.001$ \\
\hline Annlysis result & $\mathrm{p}=0.5$ & $p=0.001$ & $\mathrm{p}=0.058$ & $\mathrm{P}=0.082$ & $p<0.001$ & - \\
\hline
\end{tabular}

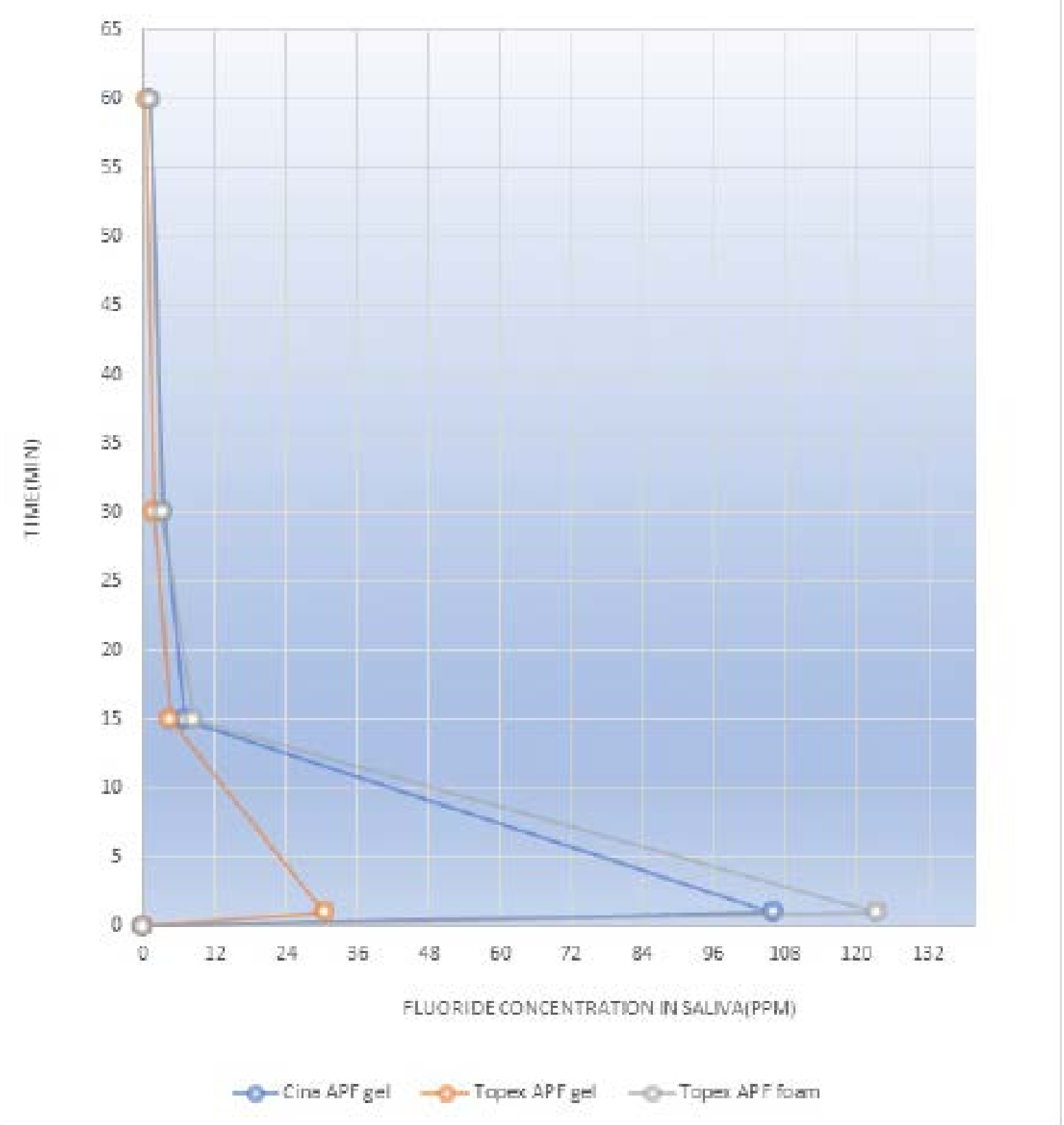

Figure 1. Salivary fluoride concentration at baseline, and at 1, 15, 30 and 60 minutes after the application of Cina APF gel, Topex $®$ APF gel and Topex $®$ APF foam. 
Salivary fluoride level at the first minute after the use of Topex ${ }^{\circledR}$ APF foam was at maximum and it was significantly different compared with the other agents $(p<0.001)$. At the 60th minute, Cina APF gel group showed the highest level, and a statistically significant difference was reported between the three agents $(\mathrm{p}<0.001)$.

In comparison of Sultan and Cina APF gels at various time points, salivary fluoride concentrations were constantly higher in Cina APF gel group, and statistically significant differences were found at time points of 1 and 60 minutes $(\mathrm{p}<0.001)$.

Collected data regarding Topex ${ }^{\circledR}$ APF foam and gel show that salivary fluoride levels in minutes 1 and 60 were significantly higher in Topex ${ }^{\circledR}$ APF gel group $(p<0.001)$. However, no statistically significant differences in salivary fluoride contents were reported at any of the time points following the application of Cina APF gel and Topex ${ }^{\circledR}$ APF foam $(p=0.885)$.

\section{Discussion:}

The results of the present study demonstrated a peak increase in salivary fluoride concentration from the first minute which remained high for about one hour. At the first minute, the maximum level of fluoride was reported after the use of Topex ${ }^{\circledR}$ APF foam $(123.5 \pm 94.11 \mathrm{ppm})$ and the difference with the other applied gels was significant. At the 15th minute, salivary fluoride content following the use of Topex ${ }^{\circledR} A P F$ foam was higher than that after the application of Cina APF gel, while the lowest level was detected after the use of Topex ${ }^{\circledR A P F}$ gel, but the difference was not significant. Moreover, at minute 30, the salivary fluoride levels in Cina APF gel and Topex ${ }^{\circledR}$ APF foam groups were close and slightly higher than that in Topex ${ }^{\circledR} A P F$ gel group but without any significant differences. Finally, maximum fluoride retention at minute 60 was related to Cina APF gel.

In an experimental study, Naumova et al. concluded that after tooth brushing, the fluoride concentration in saliva increased rapidly and dropped to the baseline level after 360 minutes. No difference was found between $\mathrm{NaF}$ and amine fluoride. ${ }^{(19)}$

Their results were almost consistent with the findings of the current study; although in our study, the salivary fluoride concentration was close to the baseline level at the 60th minute after the use of the three studied agents.
It is obvious that frequent and repeated use of products with low fluoride concentration, which promote salivary fluoride levels, is the most efficient way to prevent dental caries. Fluoride levels between 1 and $10 \mathrm{ppm}$ reduce enamel solubility, increase the remineralization rate and facilitate the precipitation of minerals on the enamel surface. ${ }^{(20)}$ Furthermore, fluoride ions inhibit the growth of Streptococcus mutans in the oral cavity. ${ }^{(21)}$

The efficacy of topical fluoride depends on the concentration, frequency and duration of application, and the type of fluoride compound. ${ }^{(19,22)}$ Topical fluoride penetrates into dental plaque by diffusion, and acts as a fluoride reservoir which could be released later. ${ }^{(22)}$ Following fluoride application, fluoride ions replace hydroxide ions in hydroxyapatite crystal structure, and the lower solubility of fluorapatite compared to that of hydroxyapatite leads to higher acid resistance of the enamel. Stronger binding forces between fluoride and apatite crystals enhance the hardness of the teeth. ${ }^{(23)}$

Topical fluoride products for professional use are available in the forms of gel, foam and varnish. Commonly used fluoride gels include APF, which contains $1.23 \%$ or 12300 ppm fluoride ions, and $2 \% \mathrm{NaF}$, which contains $0.90 \%$ or 9050 ppm fluoride ions. ${ }^{(15)}$

The most rapid uptake of APF solutions occurs during the first four minutes. Although, some manufacturers claim that their gel or foam products provide near maximum uptake in one minute, there is lack of evidence for their clinical efficacy. Therefore, according to Newbrun et al. the recommended application time is four minutes, ${ }^{(22)}$ which was considered in the present study. On the other hand, Braxton et al. showed that APF gel and foam reduced enamel demineralization irrespective of one- or four-minute application time. ${ }^{(24)}$

It has been proven that fluoride ingestion following the application of fluoride foam with tray was significantly lower than that after the application of fluoride gel. The use of a limited amount of fluoride on the tray resulted in similar fluoride retention and lower ingestion compared to the method which involves a large portion of 
fluoride followed by rinsing. ${ }^{(25)}$

APF foam allows tray application while using smaller amounts of fluoride. Foamy fluoride agents are readily dispersed within the oral cavity and are easier to apply than gel form, even when patients have fixed orthodontic appliances. Moreover, in an in-vitro research Song et al. found no significant differences between APF gel and foam regarding the amount of fluoride uptake into enamel. They stated that foam could provide an effect similar to that of gel in terms of dental caries prevention. ${ }^{(3)}$

Certainly, there are various factors contributing to oral fluoride kinetics in an open organ system like the oral cavity. Saliva secretion and content play a major role in bioavailability of fluoride. ${ }^{(26)}$ But other factors such as oral hygiene, tooth brushing duration and frequency, fluoride formulation and bioavailability of active ions, diet and adjunctive professional fluoride sources also contribute to the efficiency of the bioavailable fluoride. ${ }^{(19)}$

Further researches with larger sample sizes which also include children are recommended in order to investigate the suitable frequency of use and the effects of topical fluoride agents in dental caries prevention.

\section{Conflicts of Interest:}

The authors of this manuscript certify that they have no conflicts of interest regarding this research.

\section{Acknowledgement:}

We are thankful to those who helped us in this article including research center of Islamic Azad University, Dental Branch of Tehran.

\section{References:}

1. Shah S, Bhaskar V, Venkataraghavan K, Choudhary P, Ganesh M, Trivedi K. Efficacy of silver diamine fluoride as an antibacterial as well as antiplaque agent compared to fluoride varnish and acidulated phosphate fluoride gel: An in vivo study. Indian J Dent Res 2013; 24:(5):575-81.
2. Tschoppe P, Siegel A, Meyer-Lueckel H. Saliva substitutes in combination with highly concentrated fluorides and brushing: in vitro effects on enamel subsurface lesions. Caries Res 2010; 44(6):571-8.

3. Song W, Toda S, Komiyama E, Komiyama $\mathrm{K}$, Arakawa Y, He D, et al. Fluoride retention following the professional topical application of $2 \%$ neutral sodium fluoride foam. Int J Dent 2011;2011:1-6.

4. O'Mullane DM, Baez RJ, Jones S, Lennon MA, Petersen PE, Rugg-Gunn AJ, et al. Fluoride and Oral Health. Community Dent Health 2016;33(2):69-99.

5. Twetman S, Keller MK. Fluoride Rinses, Gels and Foams: An Update of Controlled Clinical Trials. Caries Res 2016 22;50:38-44.

6. Lin D, Huang B. Staining potential of acidulated phosphate fluoride (APF) foam on dental restorations in vitro. J Conserv Dent 2015;18(1):303.

7. Jiang H, Bian Z, Tai BJ, Du MQ, Peng B. The effect of a bi-annual professional application of APF foam on dental caries increment in primary teeth: 24-month clinical trial. J Dent Res 2005;84(3):265-8.

8. Buchalla W, Attin T, Schulte-Monting J, Hellwig E. Fluoride uptake, retention, and remineralization efficacy of a highly concentrated fluoride solution on enamel lesions in situ. J Dent Res 2002;81(5):329-33.

9. Attin T, Lennon AM, Yakin M, Becker K, Buchalla W, Attin R, et al. Deposition of fluoride on enamel surfaces released from varnishes is limited to vicinity of fluoridation site. Clin Oral Investig 2007;11(1):83-8.

10. Villena RS1, Tenuta LM, Cury JA. Effect of APF gel application time on enamel demineralization and fluoride uptake in situ. Braz Dent $\mathbf{J}$ 2009;20(1):37-41.

11. Calvo AF, Tabchoury CP, Del Bel Cury AA, Tenuta LM, da Silva WJ, Cury JA. Effect of Acidulated Phosphate Fluoride Gel Application Time on Enamel Demineralization of Deciduous and Permanent Teeth. Caries Res 2012;46(1):31-7.

12. Delbem AC, Cury JA. Effect of application time of APF and NaF gels on microhardness and fluoride uptake of in vitro enamel caries. Am J Dent 2002;15(3):169-72. 
13. American Dental Association Council on Scientific Affairs .Professionally applied topical fluoride: evidence-based clinical recommendations. J Dent Educ 2007;71(3):393-402.

14. Khattak MF, Conry JP, Ko CC. Comparison of three topical fluorides using computer imaging. J Clin Pediatr Dent 2005;30(2):139-44.

15. Kohli K, Houpt M, Shey Z. Fluoride uptake by proximal surfaces from professionally applied fluorides: an in vitro study. ASDC J Dent Child 1997;64(1):28-31.

16. Vale GC, Cruz PF, Bohn AC, de Moura MS. Salivary Fluoride Levels after Use of HighFluoride Dentifrice. Scientific World Journal 2015;302717.

17. Ingle NA, Sirohi R, Kaur N, Siwach A. Salivary fluoride levels after toothbrushing with dentifrices containing different concentrations of fluoride. J Int Soc Prevent Communit Dent 2014;4(2):129-32.

18. Ramazani N, Ahmadi R, Heidari Z, Hushmandi A. The Effect of Calcium Pre-Rinse on Salivary Fluoride After 900 ppm Fluoride Mouthwash: A Randomized Clinical Trial. J Dent(Tehran) 2013;10(4):376-82.

19 Naumova EA, Kuehnl P, Hertenstein P, Markovic L, Jordan RA, Gaengler P, Arnold WH. Fluoride bioavailability in saliva and plaque. BMC Oral Health 2012;12:3.

20. Bijella MF, Brighenti FL, Bijella MF, Buzalaf MA. Fluoride kinetics in saliva after the use of a fluoride-containing chewing gum. Braz Oral Res 2005; 19(4):256-60.

21. B Gupta, R Anegundi, P Sudha. Study of the Salivary Retention of Fluorides after the Application of Various Topical Reagents and Their Effect on Streptococcus Mutans. IJDS. 2006;5(1):1-6 22. Newbrun E. Topical fluorides in caries prevention and management: a North American perspective. J Dent Educ 2001;65(10):1078-83.

23. Byeon SM, Lee MH, Bae TS. The effect of different fluoride application methods on the remineralization of initial carious lesions. Restor Dent Endod 2016;41(2):121-9.

24. Braxton A, Garrett L, Versluis-Tantbirojn D, Versluis A. Does fluoride gel/foam application time affect enamel demineralization?J Tenn Dent Assoc 2014;94(1):28-31.
25. Opydo-Szymacze K J, Opydo J. Salivary fluoride concentrations and fluoride ingestion following application of preparations containing high concentration of fluoride. Biol Trace Elem Res 2010;137(2):159-67.

26. Naumova EA, Gaengler P, Zimmer S, Arnold WH. Influence of individual saliva secretion on fluoride bioavailability. Open Dent J 2010:27; 4:185-90. 